\title{
Bibliometric analysis of Journal of Social Health and Diabetes (JOSH Diabetes)
}

\author{
Garima Bhutani, Sanjay Kalra ${ }^{1}$, Prem Verma, Jyoti Kaushal ${ }^{2}$ \\ Department of Pharmacology, BPS GMC for women, Khanpur Kalan, Sonepat, 'Indian J Endocrinology and Metabolism, Editor-in-chief, \\ Intl J Clinical Cases and Investigations, Bharti Hospital and B.R.I.D.E., Karnal, ${ }^{2}$ Department of Pharmacology, Pt. B D Sharma, PGIMS, \\ Rohtak, Haryana, India
}

\section{A B S T R A C T}

Materials and Methods: The publications of year 2013 of JOSH Diabetes were analyzed. Total no. of articles published, type of articles, their authorship, and the coverage of various subspecialties were studied.The publications were also classified as being of Indian or foreign origin and from academic or non-academic institutions depending upon the institution of first author. Results and Conclusions: $A$ total of 2 issues of JOSH Diabetes were published in 2013 , including a total of 28 publications. Review articles and methodological issues in social health and diabetes research were published maximally.All the subspecialties were covered well, maximum being ethnography. Both academic and non-academic institutions have contributed almost equally towards this journal. The journal has been able to attract the interest of the foreign authors as well.Articles from all parts of the country have been published in JOSH Diabetes, but Haryana has contributed maximally.

Key words: Bibliometric analysis, psychosocial aspects of diabetes, publications

\section{INTRODUCTION}

The psychosocial aspects of diabetes (PSAD) care are a very important part of diabetology. ${ }^{[1]}$ The assessment and management of general, psychological, psychiatric, and social factors hugely impacts glycemic control in patients. ${ }^{[2]}$ But sadly, this specialty of diabetes has not received enough attention as yet. Concentrated, sustained, and efficient team work involving all health care professionals and stakeholders is necessary for the growth of this field. Journal of social health and diabetes is dedicated towards this goal.

JOSH-Diabetes is an applied, internationally oriented diabetes sociology journal designed to help policy makers,

\begin{tabular}{|l|l|}
\hline \multicolumn{2}{|c|}{ Access this article online } \\
\hline Quick Response Code: & Website: \\
\hline & www.josh.net \\
\hline & \\
\hline & \\
\hline
\end{tabular}

academicians, social activists, and researchers stay in touch with the social and psychological issues pertaining to diabetes management. It spreads knowledge about best practices for managing diabetes at the grass root level and encourages innovative research in the field of social aspects of diabetes management.

The article aims at performing bibliometric analysis of JOSH Diabetes, which is a peer-reviewed, semi-annual online journal published by Novo Nordisk Education Foundation (NNEF). This foundation is working to improve the social and psychological environment of people with diabetes, through research, training, and community programs. The journal publishes editorials, reviews, methodological issues in social health and diabetes research, original articles, brief communications, short reports, and letters related to social and psychological issues of diabetes management.

\section{Materials And Methods}

JOSH Diabetes issues of the year 2013, which were available online, were taken for analyzing the publication trends in this journal. The data was derived from the website of the journal, which gives link to the previous issues. 
The articles published were analyzed for the type of the articles (editorials, review articles, original articles, methodological issues in social health and diabetes research, brief communications, short reports, and letters to the editor). Certain types of articles which appear infrequently were clubbed with larger categories, for ease of analysis. Methodological issues in social health and diabetes research were grouped with review articles. Brief communications and short reports were clubbed together.

The categorization of articles according to the subspecialties was made and modified in consultation with the editor. The articles were divided into 8 major groups, namely ethnography, health care provision and guidelines, qualitative research, clinical diabetology, psychiatry, TPE (therapeutic patient education), KAP (knowledge, attitude and practice), and bibliometry. Divergent opinion was resolved by consensus between authors.

The articles were later categorized as being of Indian or foreign origin, and from academic or non-academic institutions depending upon the institution of the first author. The articles were also divided according to the state of origin.

\section{RESULTS}

In year 2013, two issues of JOSH Diabetes were published comprising a total of 28 publications. These included

\begin{tabular}{lccc}
\hline Table 1: Number of articles published in JOSH Diabetes in & $\mathbf{2 0 1 3}$ \\
\hline & July-Dec 2013 & Jan-June 2013 & Total \\
\hline Editorials & 2 & 2 & 4 \\
Review articles and & 6 & 5 & 11 \\
methodological issues & & & \\
$\begin{array}{l}\text { Original articles } \\
\text { Brief communications }\end{array}$ & 4 & 4 & 5 \\
$\begin{array}{l}\text { and short reports } \\
\text { Letter to the editor }\end{array}$ & 2 & & 6 \\
Total & 16 & 12 & 2 \\
\hline
\end{tabular}

4 editorials, 11 review articles and methodological issues, 5 original articles, 6 brief communications and short reports, 2 letters to the editor. There were a total of 12 publications in Jan-June issue, which rose to 16 in July-Dec issue. Review articles and methodological issues in social health and diabetes research have been published maximally [Table 1].

The publications of JOSH Diabetes covered many subspecialties. Maximum coverage (32\%) was received by ethnography followed by health care provision and guidelines (29\%) [Table 2 and Figure 1].

A very good contribution by the foreign countries was made towards the journal in both July-Dec 2013 (37.5\%) and JanJune 2013 (41.66\%) issue. The countries who got their work published in JOSH Diabetes were USA, China, Denmark, Nigeria, Egypt, Nepal, Qatar, Tunisia, and Pakistan [Table 3].

Slightly more contribution has been received from academic (53.57\%) sector as compared to non academic (46.42\%) sectors in year 2013.

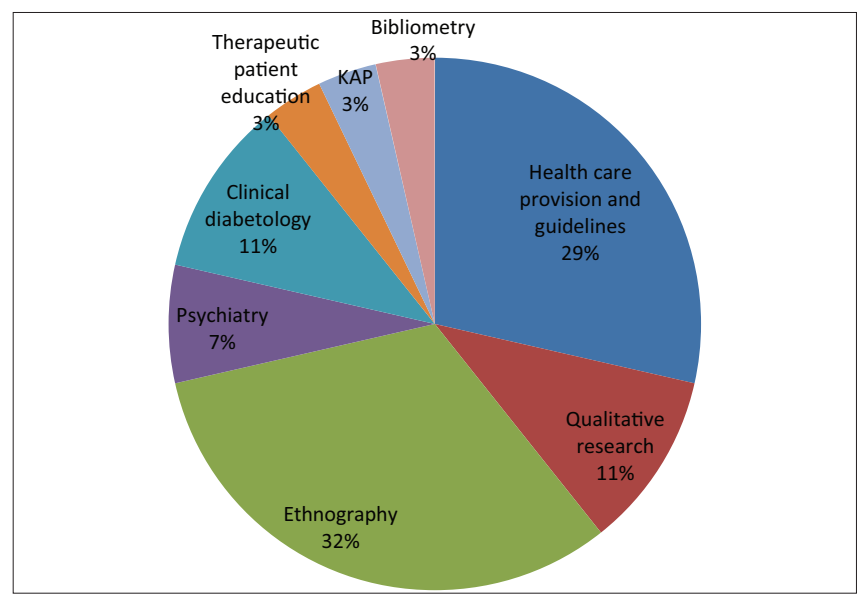

Figure 1: Graphical representation of subspecialty coverage in $\mathrm{JOSH}$ Diabetes in 2013

\begin{tabular}{|c|c|c|c|c|c|c|}
\hline Subspecialties & Editorials & $\begin{array}{l}\text { Review articles and } \\
\text { methodological issues }\end{array}$ & $\begin{array}{l}\text { Original } \\
\text { articles }\end{array}$ & $\begin{array}{l}\text { Brief communications } \\
\text { and short reports }\end{array}$ & $\begin{array}{l}\text { Letter to } \\
\text { the editor }\end{array}$ & Total \\
\hline Ethnography & 0 & 5 & 0 & 3 & 1 & $9(32 \%)$ \\
\hline $\begin{array}{l}\text { Health care provision } \\
\text { and guidelines }\end{array}$ & 2 & 2 & 1 & 2 & 1 & $8(29 \%)$ \\
\hline Qualitative research & 0 & 2 & 1 & 0 & 0 & $3(11 \%)$ \\
\hline Clinical diabetology & 1 & 1 & 0 & 1 & 0 & $3(11 \%)$ \\
\hline Psychiatry & 1 & 1 & 0 & 0 & 0 & $2(7 \%)$ \\
\hline $\begin{array}{l}\text { TPE (therapeutic } \\
\text { patient education) }\end{array}$ & 0 & 0 & 1 & 0 & 0 & $1(3 \%)$ \\
\hline $\begin{array}{l}\text { KAP (knowledge, } \\
\text { attitude, and practice) }\end{array}$ & 0 & 0 & 1 & 0 & 0 & $1(3 \%)$ \\
\hline Bibliometry & 0 & 0 & 1 & 0 & 0 & $1(3 \%)$ \\
\hline Total & 4 & 11 & 5 & 6 & 2 & 28 \\
\hline
\end{tabular}


A total of 9 states and union territories from different parts of India have contributed their share towards this journal in its initial year. Maximum publications were received from Haryana (29\%) followed by Karnataka (17\%) [Figure 2].

\section{DISCUSSION}

This bibliometric study has tried to assess and analyze the publication trends of journal of social health and diabetes (JOSH diabetes). It is a new journal dedicated towards the dissemination of knowledge of psychosocial aspects of diabetes (PSAD). The journal is handling a nascent field of medicine, which unfortunately was untouched

\begin{tabular}{|c|c|c|c|c|}
\hline & \multicolumn{2}{|c|}{ July-Dec 2013} & \multicolumn{2}{|c|}{ Jan-June 2013} \\
\hline & Indian & Foreign & Indian & Foreign \\
\hline Editorials & 2 & 0 & 2 & 0 \\
\hline $\begin{array}{l}\text { Review articles and } \\
\text { methodological issues }\end{array}$ & 2 & 4 & 2 & 3 \\
\hline Original articles & 4 & 0 & 1 & 0 \\
\hline $\begin{array}{l}\text { Brief communications } \\
\text { and short reports }\end{array}$ & 1 & 1 & 2 & 2 \\
\hline Letter to the editor & 1 & 1 & 0 & 0 \\
\hline Total (\%) & $10(62.5 \%)$ & $6(37.5 \%)$ & 7 (58.33\%) & $5(41.66 \%)$ \\
\hline
\end{tabular}

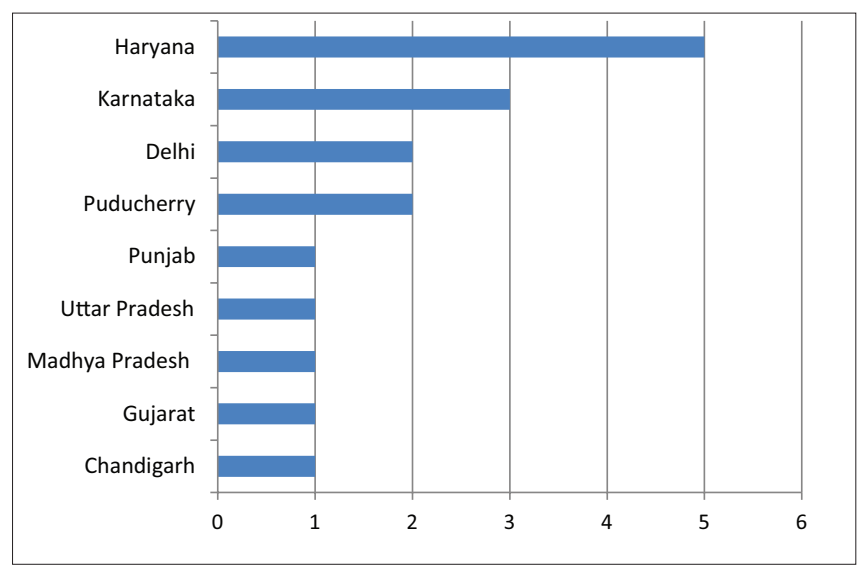

Figure 2: Graphical representation of relative contributions of different states towards JOSH Diabetes till now. It adds a new psychosocial angle to conventional clinical medicine like American diabetes association and European association for study of diabetes (ADA /EASD) guidelines, and to critical care. JOSH Diabetes is a truly international journal, which is receiving attention and enthusiasm from many continents like America, Africa, rest of Asia, and Europe. A lot of researchers around the globe have shown interest in the journal as seems evident by the multi-author, multi-institutional, and multi-country nature of articles. The journal has an open editorial policy as suggested by lot of published original research articles, inclusion of articles from all over the country, and very good coverage of all subspecialties. Highest contribution towards the journal has been done by Haryana. Non-academic sector has also shown much enthusiasm in this journal. In nutshell, JOSH Diabetes is one of the few biomedical journals to accept and promote qualitative research.

\section{CONCLUSIONS}

The bibliometric analysis proves that JOSH Diabetes is working well to spread light on the expanding horizons of diabetes management. It is hoped that the journal is able to impart the much desired attention to the psychosocial aspects of diabetes (PSAD) care.

\section{REFERENCES}

1. Peyrot M, Rubin RR, Lauritzen T, Snoek FJ, Matthews DR, Skovlund SE. Psychosocial problems and barriers to improved diabetes management. Results of Cross National Diabetes Attitudes, Wishes and Needs (DAWN) Study. Diabet Med 2005;22:1379-85.

2. Kalra S, Sridhar G R, Balhara YS, Sahay RK, Bantwal G, Baruah MP, et al. National recommendations: Psychosocial management of diabetes in India. Indian J Endocr Metab 2013;17:376-95.

How to cite this article: Bhutani G, Kalra S, Verma P, Kaushal J. Bibliometric analysis of Journal of Social Health and Diabetes (JOSH Diabetes). J Soc Health Diabetes 2014;2:37-9.

Source of Support: Nil. Conflict of Interest: None declared. 